\title{
Functionalized Calixarenes Drug-Sensing Receptor: A Review
}

\author{
Keyur Bhatt ${ }^{1 *}$, Anita Kongor ${ }^{2}$ and Mohd Athar ${ }^{3}$ \\ 1Department of Chemistry, Ganpat University, India \\ 2Department of Chemistry, Gujarat University, India \\ ${ }^{3}$ School of Chemical Sciences, Central University of Gujarat, India
}

\section{Mini Review \\ Volume 2 Issue 2}

Received Date: July 02, 2018

Published Date: July 11, 2018

*Corresponding author: Keyur Bhatt, Department of Chemistry, Mehsana Urban Institute of Sciences, Ganpat University, Kherwa, India, Email: drkdbhatt@outlook.com

\section{Abstract}

This review gives a comprehensive insight on the functionalized calixarenes in the field of drug sensing. The spectacular feature of calixarenes with three-dimensional surface makes it capable as sensor for a drug. Under the calixarene scaffold, there are reports on different sensing applications which include calixarene functionalized nanoparticles, drug interactions which are also reviewed in this article. Herein, a brief survey is presented which includes sensing of toxic heavy metal ion, molecules and drugs interactions.

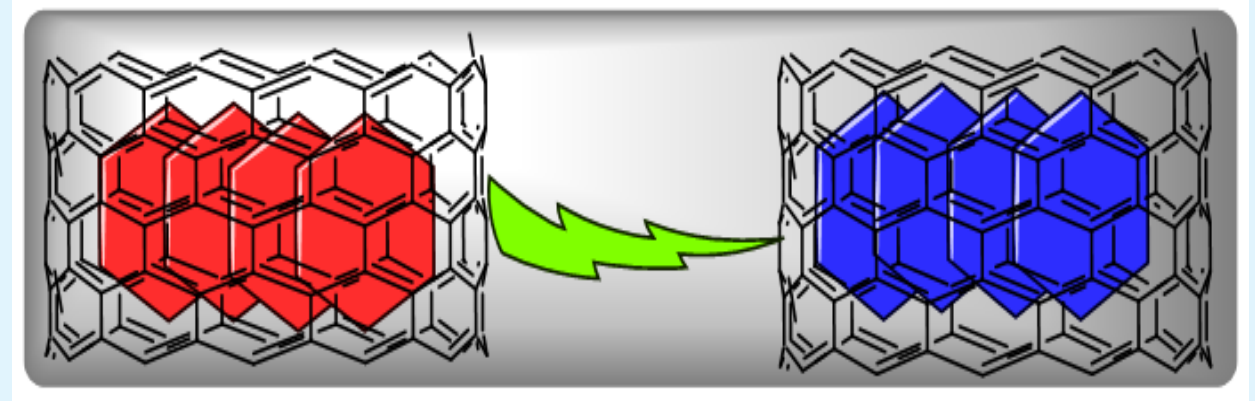

Keywords: Sensor, calix system, Metal ions, Drug interaction.

\section{Introduction}

Calixarenes have been first introduced by Gutsche D in 1978 [1]. The word "calix" means a vase and the word "arene" refers to any aromatic building unit. Structurally, calixarenes possess an upper rim, middle annulus and a lower rim. According to reports, functionalized calixarenes includes crown and fullerene-bearing calixarenes, bridged calixarenes, polymeric calixarenes, modified calixarenes, and hetero-and hetera-calixarenes [2]. Calixarenes can be chosen as efficient sensor because of its chemical stability, selective complexation ability and low toxicity properties $[3,4]$. Due to their unlimited functionalization properties, calixarene functionalized nanoparticles are also reported to act as selective sensors for different ions and molecules [5]. The interaction and administration of drug molecules to the body requires them to be framed into a suitable dosage form that may be dictated by the fundamental properties of the drug or the site of the drug target delivery and disease being treated [6]. Drug solubilization and delivery using calix [n] arene aggregates or calyx [n] arenes that have been 


\section{Medicinal \& Analytical Chemistry International Journal}

assembled into or form part of larger supramolecular structures has been reported [7].

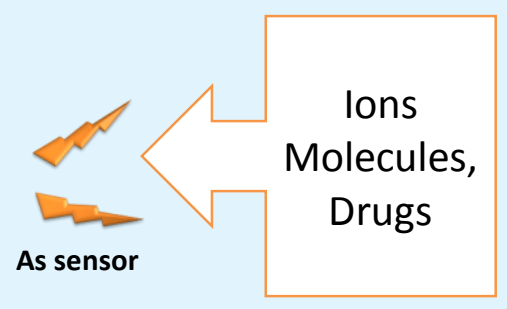

Figure 1: Calixarene as sensing element.

The basic principle of functionalized calixarenes to act as sensor lies behind any changes or tracking any kind of signal detection in its environment. The complexation behaviour of metal cations and molecules with calix [4] resorcinarene was studied by spectophotometry and spectrofluorometry $[8,9]$. The use of functionalized oxacalixarene as a fluorescent sensor for the selective and sensitive detection of ions like copper and cerium and molecules like pendimethalin has also been reported $[10,11]$. Different thiacalixarene derivatives have also been explored for the detection of mercury and cobalt ion based on fluorescence mechanism [12,13]. An ionophore based on schiff-based calixarene has been used for sensor Ag (I) ions [14].Threat agents like nitro aromatic compounds have also been selectively sensed by Dipyrenylcalix [4] arene [15]. Sensing and recognition of commercially pertinent molecules is ongoing research processes that ubiquitously play roles in biological, medical, environmental, and chemical sciences [16]. With calixarene, it's possible to tailor the complementary structural components with optimal recognition property between the host and guest. Given the spatial distribution and multitude of potential binding site provided by the calixarene, it can allow the rational control of the binding properties. The fact that both the upper and lower rims of the expanded or extended calixarene can be functionalized; it successively tailors pre organized supramolecular architecture for flanking the chemical analytes in the binding sites. Among the binding forces, non-covalent interactions including hydrogen-bonding and weak van der Waal interactions are particularly useful. The calixarene receptors comprising the functional groups such as amides, ureas, anthracene, thiourea, quinoline, etc enable the calixarenes to selectively bind the specified analytes via non-covalent interactions. Other than experimental platforms to perform such chemical sensing, state-of-art computational methods are nowadays used. Urea and thiourea substituted calixarene has been inspected by the Density Functional Theory (DFT) method to prioritize the binding selectivity among an array of spherical and linear anions [17]. Of special interest are the luminescent properties of some of the functionalized calixarene (chromophore or fluorophore) which allow the visual handing and commercial ease of such framework. Upon binding with a guest, the change of the spectral properties would give rise to a sensing mechanism. Using dispersion corrected DFT and KohnSham molecular orbital theory, Ortolan, et al. explored the role of physical factors that affect the noncovalent interactions in anion sensing on calixarene. They report that the strength of the host-guest interaction can be enhanced through the introduction of strongly electronwithdrawing groups, triazine units and coordination of a metal to the arene rings [18]. Murphy et al has used the DFT to investigate the effect of methylation of the lowerrim tetraphenolic pocket of calyx [4] arene on the binding of small gaseous molecules such as $\mathrm{H}_{2}, \mathrm{O}_{2}, \mathrm{~N}_{2}, \mathrm{H}_{2} \mathrm{O}, \mathrm{CO}_{2}$, $\mathrm{NH}_{3}, \mathrm{H}_{2} \mathrm{~S}, \mathrm{~N}_{2} \mathrm{O}, \mathrm{HCN}$, and $\mathrm{SO}_{2}$ [19]. Moreover, DFTGrimme's dispersion correction-Becke-Johnson damping functions (D3BJ) scheme was applied the unveil the mechanistic insights the recognition of anions by the electron deficient cavity using the heterocalixarene rings [20].

\section{References}

1. Gutsche C (1998) Calixarenes Royal Society of Chemistry, Cambridge, UK, 1989. CD Gutsche Calixarenes Revisited in Royal Society of Chemistry, Cambridge.

2. Agrawal Y, Pancholi JP, Vyas J (2009) Design and synthesis of calixarene 68: 745-768

3. Bhatt KD, Makwana BA, Vyas DJ, Mishra DR, Jain VK (2014) Selective recognition by novel calix system: ICT based chemosensor for metal ions. Journal of Luminescence 146: 450-457.

4. Bhatt KD, Shah HD, Panchal M (2017) A switch-off fluorescence probe towards $\mathrm{Pb}$ (II) and cu (II) ions based on a calix [4] pyrrole bearing amino-quinoline group. Luminescence 32(8): 1398-1404.

5. Kongor AR, Mehta VA, Modi KM, Panchal MK, Dey SA, et al. (2016) Calix-Based Nanoparticles: A Review. Topics in Current Chemistry 374(3): 28. 


\section{Medicinal \& Analytical Chemistry International Journal}

6. Hoskins C, Curtis A (2015) Simple calix [n] arenes and calix [4] resorcinarenes as drug solubilizing agents. J Nanomed Res 2(3): 1-8.

7. Sansone F, Baldini L, Casnati A, Ungaro R (2010) Calixarenes: from biomimetic receptors to multivalent ligands for biomolecular recognition. New Journal of Chemistry 34(12): 2715-2728.

8. Bhatt KD, Gupte HS, Makwana BA, Vyas DJ, Maity D, et al. (2012) Calix Receptor Edifice; Scrupulous Turn Off Fluorescent Sensor for $\mathrm{Fe}(\mathrm{III}), \mathrm{Co}(\mathrm{II})$ and $\mathrm{Cu}(\mathrm{II}), \mathrm{J}$ Fluoresc. J Fluoresc 22(6): 1493-1500.

9. Makwana BA, Darjee S, Jain VK, Kongor A, Sindhav G, et al. (2017) A comparative study: Metal nanoparticles as fluorescent sensors for biomolecules and their biomedical application. Sensors and Actuators B: Chemical 246: 686-695.

10. Panchal M, Athar M, Jha P, Kongor A, Mehta V, et al. (2017) Quinoline appended oxacalixarene as turn-off fluorescent probe for the selective and sensitive determination of $\mathrm{Cu} 2+$ ions: A combined experimental and DFT study. Journal of Luminescence 192: 256-262.

11. Panchal M, Athar M, Jha P, Kongor A, Mehta V, et al. (2016) Turn-off fluorescence probe for the selective determination of pendimethalin using a mechanistic docking model of novel oxacalix [4] arene. RSC Advances 6(58): 53573-53577.

12. Bhatt KD, Shah H, Modi KM, Kongor A, Panchal M, et al. (2017) Novel calix [4] pyrrole assembly: Punctilious recognition of $\mathrm{F}-$ and $\mathrm{Cu}+2$ ions. Journal of Molecular Structure 1149: 299-306.

13. Bhatt KD, Vyas DJ, Makwana BA, Darjee SM, Jain VK, et al. (2016) Turn-on fluorescence probe for selective detection of $\mathrm{Hg}$ (II) by calixpyrrole hydrazide reduced silver nanoparticle: Application to real water sample. Chinese Chemical Letters 27(5): 731-737.

14. Mahajan R, Kaur I, Sharma V, Kumar M (2002) Sensor for silver (I) ion based on Schiff-base-p-tertbutylcalix [4] arene. Sensors 2(10): 417-423.

15. Lee YH, Liu H, Lee JY, Kim SH, Kim SK, et al. (2010) Dipyrenylcalix [4] arene-A Fluorescence-Based Chemosensor for Trinitroaromatic Explosives. Chemistry-A European Journal 16(20): 5895-5901.

16. Sun XH, Li W, Xia PF, Luo HB, Wei Y, et al. (2007) Phenyl-calix [4] arene-based fluorescent sensors: cooperative binding for carboxylates. The Journal of organic chemistry 72(7): 2419-2426.

17. Mehta V, Athar M, Jha P, Kongor A, Panchal M, et al. (2017) A turn-off fluorescence sensor for insensitive munition using anthraquinone-appended oxacalix [4] arene and its computational studies. New Journal of Chemistry 41(12): 5125-5132.

18. Ortolan AO, Østrøm I, Caramori GF, Parreira RL, Da Silva EH, et al. (2018) Tuning Heterocalixarenes to Improve Their Anion Recognition: A Computational Approach. The Journal of Physical Chemistry A. 122(12): 3328-3336.

19. Murphy P, Dalgarno SJ, Paterson MJ (2017) Systematic Study of the Effect of Lower-Rim Methylation on Small Guest Binding within the Host Cavity of Calix [4] arene. The Journal of Physical Chemistry A 121(41): 7986-7992.

20. Ortolan AO, Caramori GF, Bickelhaupt FM, Parreira RL, Muñoz-Castro A, et al. (2017) How the electrondeficient cavity of heterocalixarenes recognizes anions: insights from computation. Physical Chemistry Chemical Physics 19(36): 24696-24705.

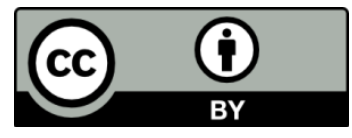

